\title{
FORUM FOR CARS AND TRUCKS
}

Dear Reader,

a total of 388 people attended the first International Engine Congress, which was organised by ATZlive and the VDI Knowledge Forum. The event in BadenBaden fully lived up to their expectations. During the course of the 46 specialist presentations and keynote speeches plus a lively panel discussion, the congress focused in detail on the combustion engine from the perspective of cars and commercial vehicles. In a deliberate move, specific sessions were arranged on the subject of commercial vehicles and, as a result of the very positive feedback received, a separate commercial vehicle conference will take place from 2015 onwards under the umbrella of the International Engine Congress. An advisory committee of experts will ensure that the quality of the subjects and the presentations on both cars and commercial vehicles is maintained over the years to come.

What were the findings of the congress? Firstly, that combustion engines are leading the way towards low-emission, $\mathrm{CO}_{2}$-neutral transport. Secondly, that we have not yet fully exploited the potential of friction, gas exchange, the combustion process and exhaust gas treatment. And thirdly, that we can only achieve our objectives by taking an integrated approach to the engine, the powertrain and the vehicle as a whole.

On 24 and 25 June the International chassis.tech plus Symposium organised by ATZlive will be taking place at the Bayerischer Hof in Munich. Around 500 participants from three continents are expected to attend the main interdisciplinary session and the four separate strands of the chassis.tech plus which covers almost every aspect of automotive engineering from powertrains to chassis, wheels, brakes and steering and gives a clear view of the complete vehicle. The chassis.tech plus will also be considering ways of increasing the efficiency of cars and commercial vehicles, but from a different perspective.

ATZ and her sisters MTZ and ATZelektronik have set themselves the goal of focusing more closely on the world of trucks. More specialist articles on this subject, the International Engine Congress and the chassis.tech plus Symposium represent important steps in the right direction. Another major feature is our ATZextra special issue for the IAA Commercial Vehicles show in Hannover in September, which will be "put on the road” jointly by ATZ and MTZ. We are already looking forward to receiving contributions from your organisations.

With best regards,

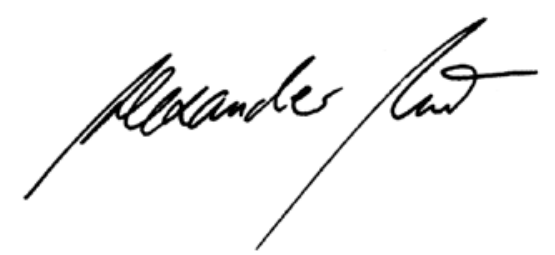

DR. ALEXANDER HEINTZEL, Editor in Chief Wiesbaden, 22 April 2014

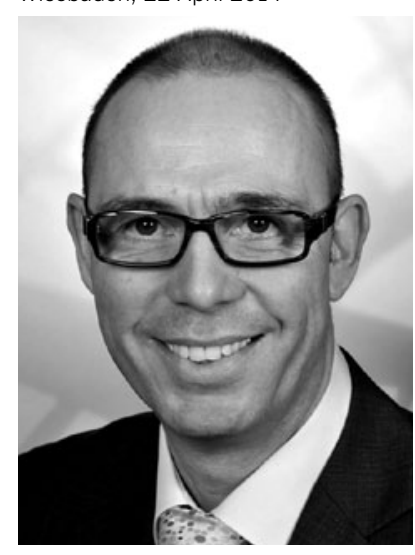

